Journal of

Cardiology and Vascular Medicine

\title{
Positive Troponin and Negative Stress Test: Why the Conundrum?
}

\author{
Sonia Mishra ${ }^{1}$, Ajay Mishra ${ }^{2}$, Jagdish P Mishra ${ }^{3, *}$ \\ ${ }^{1}$ Thomas Jefferson University, Philadelphia, PA 19107 \\ ${ }^{2}$ Georgetown University, Washington, DC 20057 \\ ${ }^{3}$ Chief of Cardiology, United Memorial Medical Center, Batavia, NY, USA
}

${ }^{*}$ Corresponding author: Jagdish P Mishra, Chief of Cardiology, United Memorial Medical Center, Batavia, NY, USA E-mail: jpmish@gmail.com

Received Date: December 12, 2016 Accepted Date: January 06, 2017 Published Date: January 10, 2017

Citation: Sonia Mishra, et al. (2017) Positive Troponin and Negative Stress Test: Why the Conundrum?. J Cardio Vasc Med 3: $1-8$.

\begin{abstract}
A 70-year old man otherwise physically active and healthy except having a history of gastroesophageal reflux presented to the local emergency room (ER) with chest discomfort while getting ready to go to work in the morning. Symptoms were recurrent but mild, however he did go to work. Symptoms continued to recur at work and therefore decided to come to ER. Symptoms responded to sublingual nitroglycerin and he was admitted with the new onset angina/acute coronary syndrome. ECG showed nonspecific ST/T changes and the first troponin was normal. He was advised to undergo coronary angiography which he refused but agreed to have a treadmill stress test. He did well with his stress test. His second troponin was drawn in the meantime. He insisted on going back to work.

His second troponin came back elevated at 4.6. He was called right away to come back to the hospital and the next day, his coronary angiography revealed $75 \%$ proximal left anterior descending artery and $80 \%$ first diagonal disease requiring two stents.
\end{abstract}

Why did the treadmill stress test fail to reproduce his chest pains and/or why ST/T changes diagnostic of ischemia not seen on his treadmill ECG when his presentation was considered a high risk scenario of acute coronary syndrome?

\section{Introduction}

\section{Let us look at the following five case scenarios:}

1. National Institute for Health and Clinical Excellence (NICE) guidelines: "Do not use exercise ECG to diagnose or exclude stable angina for people without known CAD (coronary artery disease)." (BMJ: 2010) and yet exercise ECG is still the most commonly used diagnostic test for this indication.

2. 'Bill Clinton Syndrome': 2004: President Bill Clinton had some chest tightness/chest pains one evening in 2004 and was taken to a hospital in NY City. His initial tests were normal and he was sent home. It was thought that his symptoms could have been GI-related (Gatrointestinal). Next morning he returned to the hospital with similar symptoms and further testing including coronary angiography revealed multiple blockages leading to multi-vessel cardiac bypass surgery! This dilemma and conundrum we feel and face every day.

(C)2017 The Authors. Published by the JScholar under the terms of the Creative Commons Attribution License http://creativecommons.org/licenses/ by/3.0/, which permits unrestricted use, provided the original author and source are credited.
3. 'Tim Russert Test': 2008: Tim Russert, a wellknown journalist for NBC died from massive heart attack/ sudden cardiac death while at work. He had a normal treadmill stress test 6 weeks prior to his death! As a matter of fact, his stress test was reported as being excellent. How come, that 'excellent' stress test could not predict such a massive heart attack within 6 weeks? Presumably he had massive blockage of his LAD (left anterior descending) artery on autopsy (also called a 'widow-maker')!

President Bill Clinton and the journalist Tim Russert both were 58 at the time of their events but with very different outcome!

We feel and face this dilemma/conundrum almost on a daily basis.

4. 'We Docs do not get sick' Syndrome: Dr Marc Wallack, a well-known surgical oncologist in NY City, a regular and avid marathon runner with normal cholesterol and blood pressure metrics used to have an annual stress test with an excellent report. 
In 2010, he had a normal stress test and 6 months later, he ended up having a quadruple bypass cardiac surgery! Once upon a time, he was married to Jamie Colby, a news reporter and anchor for Fox News Channel. After his cardiac surgery, they together wrote a book, "Back to Life after a Heart Crisis." We see, face and fume over this dilemma and conundrum every day!

5. 'George Bush controversy': 2013: President GW Bush had been physically very active and is a mountain biker. He was presumably getting a stress test every year. In 2013, he was said to have failed the stress test which led to coronary angiography and as per the report, he had at least one 95\% coronary artery blockage requiring a stent placement!

Conundrum: 1. How come he was having a stress test every year when he was totally asymptomatic and physically very active and the current guidelines advise not to perform a stress test in such a situation?

2. Why was he given a stent when he had no symptoms? How would we know if he was feeling better now after a stent placement when he had no symptoms to begin with?

For his cardiac care in 2013, Dr. Steve Nissen, a prominent cardiologist rightly called, "This is really American medicine at its worst." For his coronary stenting, Dr. David Brown, another cardiologist said "GWB is now the poster child of inappropriate use of stenting."

If we are unable to figure out as to how best to take care of our US presidents and other well-known personalities, just imagine the case scenario for our ordinary citizens!

Over the decades, the cardiac care had continued to improve significantly, however we need to do much better job as coronary artery disease (CAD) remains to be the leading cause of death in the United States with one American experiencing coronary event every 34 seconds [1]. This disease state costs the US about $\$ 110$ Billion each year [2]. Of all the people who die suddenly (sudden cardiac death, SCD), 50\% of men and $64 \%$ of women have had no previous signs or symptoms of CAD [3]. Even though the coronary angiography is still considered the gold standard for diagnosing CAD, it is invasive, expensive and has serious associated complications including acute myocardial infarction, strokes, bleeding and arrhythmia [4]. There are a number of non-invasive diagnostic cardiac tests available, however when so much is at stake [1-3], we need to have the tests with utmost sensitivity and specificity to make the right diagnosis the very first time. Morbidity, mortality and chances of malpractice are very high when we miss the diagnosis of ischemic heart disease.

Notable non-invasive functional tests available to help us make the diagnosis are: 1 . Treadmill stress test (symptoms of chest pressure and ECG changes of ischemia), 2. Stress Echocardiography (wall motion abnormalities), 3. Myocardial Perfusion Imaging (perfusion defects) and 4. Cardiac Magnetic Resonance Imaging (myocardial metabolism and viability).
Of all the available modalities, the Treadmill Test is still the oldest, least expensive and most commonly used form of stress testing and therefore we must know everything about this test, use it in the right patient setting, and improve and improvise it as much as we can. However, before we can do that, I would like to write my personal experience with a patient whom I met the first time in the hospital recently:

\section{Case Report}

CK is a 70-year old man with history of GERD (gastroesophageal reflux disease) otherwise quite healthy and physically active presented one day to the local emergency room with chest pains. He said he woke up in the morning and was feeling some chest pressure, back discomfort and some jaw pains. While shaving, he continued to feel those symptoms. He did go to work, however because the symptoms continued to recur, he decided to come to ER by noon. He never has had symptoms like these before. There were no associated symptoms of palpitations, sweating, pre-syncope or arm pains. He was not known to have CAD (coronary artery disease), myocardial infarction, heart failure, hypertension, diabetes, dyslipidemia or tobacco smoking. He did not take any medications except one pill for his GERD. His symptoms that morning were unlike his occasional symptoms from GERD. His initial ECG in the ER showed some ST depression in precordial leads. There was no old ECG for comparison and his first troponin was normal. By then his symptoms had already subsided in ER with one sublingual nitroglycerin. At that point I saw him in cardiac consultation.

He did not have many cardiac risk factors. However his early morning symptoms, continued for morning hours while at work, some ST changes in ER and relief of his symptoms with a sublingual nitroglycerin were good enough clinical markers for me to call this as 'new onset angina/acute coronary syndrome' and recommend to him to undergo diagnostic coronary angiography directly, in addition to continued medical therapy. He was symptom free at that time and was rushing to get back to work and wanted to consider a treadmill stress test only at that point. He refused to have coronary angiography. I somewhat unwillingly agreed to do a low level of treadmill test (in my mind I was thinking that he will most likely develop those symptoms of chest pressure/pains and/or develop some significant ST changes). My plan was to make him walk on the treadmill only for a few minutes. However he continued to do well! He developed no chest pressure/pains, no palpitations or diaphoresis. His subsequent ECG before the treadmill had improved and during exercise, at peak or during recovery, no ST/T changes of ischemia noted! He obtained the work load of 7.5 METS. As a matter of fact, I was surprised for his test being unremarkable.

At that point, still suspecting him of CAD with new onset angina, I prescribed him Aspirin, Metoprolol, a Statin, as needed sublingual Nitro and advised him to return to my office within a week for follow up. 
He left the hospital soon thereafter. In next few hours, I was called by the hospitalist that his second troponin (which was drawn before his stress test) had come back abnormally high at 4.6. I called the patient right away and spoke to him and his wife while they were out having dinner at a restaurant and explained to them that he had a heart attack and needed to come back to the hospital. His wife drove him back and he was admitted right away. I had already called and explained the case scenario to an interventional cardiologist. Because he was stable enough and chest pain free, the decision was made to admit him, treat him medically overnight and do coronary angiography next morning.

He was found to have 75\% proximal LAD (left anterior descending) artery and $80 \%$ 1st Diagonal disease and both lesions were stented. He has been doing well thereafter.

Since then, I have been having the recurring thoughts and the most intriguing questions of my life: Why did he not develop the same or worse chest pains while on the treadmill, all the same symptoms he had that morning before coming to the hospital? After all, I gave him a good amount of treadmill walk, definitely much more than walking to the bathroom, shaving and having chest discomfort! Why did he not show any ST/T changes suggestive or diagnostic of ischemia? Having two severe blockages of his epicardial coronaries and having positive troponins (myocardial infarction), how come he did not develop any serious arrhythmia on the treadmill? My initial plan that he would fail the treadmill test at a very low level did not work at all. Why not?

We have the hospital protocol of having at least two serial troponins being negative prior to doing a treadmill stress test on anyone. In this case, I proceeded with a treadmill test with only one troponin being negative for two reasons: One, he was unwilling to have coronary angiography at my initial visit. Two, I was more than sure that he would fail a treadmill test at low level and then he would consider having coronary angiography in the setting of new onset angina.

Most of the literature and all the US and European guidelines dictate this case scenario of elevated troponin and stress test in that setting as being Class III and Level of Evidence as C: meaning the stress test is contraindicated and could be harmful.

I have not found any case like this on initial search in the literature and therefore I would like to point out this as the first case being reported as having a normal treadmill stress test in the setting of documented myocardial infarction with elevated troponin and thereafter documented severe CAD requiring two stents.

\section{Discussion}

Beforewedelveinto this case scenarioany further, Iwould like to review the pertinent details of the treadmill stress test: Pretest Probability of CAD:

The single most important concept in CAD diagnosis is the understanding of Bayes' theorem of conditional probability [5] which I can summarize in one sentence: "The posttest likelihood of a disease depends on the pretest likelihood of that disease in a population." Therefore the sensitivity and specificity of a test will vary dramatically depending on what kind of population we pick to do a certain test.

In case of CAD diagnosis related to Bayes' theorem, the most important variables included to determine the pretest probability are: Symptoms of chest pains/pressure, Age, Gender and Framingham Cardiac Risk Factors (hypertension, high cholesterol, tobacco smoking and Diabetes).

1. Chest Pains/Pressure: There are three kinds of chest pains: Typical angina, Atypical angina and Nonanginal pains.

According to Bayes' theorem and pretest probability, the prevalence of CAD in persons with typical angina is about $90 \%$, whereas atypical angina shows a $50 \%$ prevalence and nonanginal chest pains of about $15 \%$ prevalence [6].

2. Age and Gender: Based on the concept of Bayes' theorem, the pretest likelihood in a 55-year old man with typical angina is $92 \%$, but the likelihood in a 35 -year old woman with atypical angina is only $4 \%[6]$.

3. Framingham Cardiac Risk Factors: For patients without known CAD, the Framingham Risk Score is useful in identifying patients' 10-year risk for a major coronary event [7]. Depending on the score, a patient is assigned to a low-, intermediate-, and high-risk category. 
Table 1: Pretest Probability of CAD

\begin{tabular}{|l|l|l|l|l|l|}
\hline Age, (years) $\dagger$ & Gender & $\begin{array}{l}\text { Typical or Definite } \\
\text { Angina Pectoris }\end{array}$ & $\begin{array}{l}\text { Atypical or } \\
\text { Probable Angina } \\
\text { Pectoris }\end{array}$ & $\begin{array}{l}\text { Nonanginal Chest } \\
\text { Pain }\end{array}$ & No Symptoms \\
\hline $30-39$ & Male & Intermediate & Intermediate & Low & Very low \\
\hline & Female & Intermediate & Very low & Very low & Very low \\
\hline $40-49$ & Male & High & Intermediate & Intermediate & Low \\
\hline & Female & Intermediate & Low & Very low & Very low \\
\hline $50-59$ & Male & High & Intermediate & Intermediate & Low \\
\hline & Female & Intermediate & Intermediate & Low & Very low \\
\hline $60-69$ & Male & High & Intermediate & Intermediate & Low \\
\hline & Female & High & Intermediate & Intermediate & Low \\
\hline
\end{tabular}

Adapted from Gibbons RJ, Balady GJ, Beasley JW, et al: ACC/AHA guidelines for exercise testing: Executive summary. A report of the American College of Cardiology/American Heart Association Task Force on Practice Guidelines (Committee on Exercise Testing). Circulation 1997;96:345-354.

${ }^{*}$ High probability, $>90 \%$; intermediate, $10 \%-90 \%$; low, $<10 \%$; very low, $<5 \%$.

$\dagger$ No data exist for patients aged $>30$ years or $<69$ years, but it can be assumed that the prevalence of CAD increases with age. In a few cases, patients at the extremes of each decade may have probabilities slightly outside the high or low range.

As per 1-3 characteristics noted above, one can determine the pretest likelihood of CAD and thus after having a stress test, one can come up with the result/post-test likelihood of CAD. For example, a 45 -year-old man with atypical angina has a pretest likelihood of CAD of $45 \%$. If the stress test shows a 1.0 mm ST depression, based on this concept, the post-test likelihood goes up to $65 \%$. The same finding in a female will give the post-test likelihood of only $25 \%$. Conversely, if $2.5 \mathrm{~mm}$ of the ST segment is observed, the corresponding post-test likelihood would be $97 \%$ for the man and $87 \%$ for the woman.

According to Bayes' theorem, the diagnostic power of exercise testing is maximal when the pretest probability of CAD is intermediate (10-90\%). Therefore most of the stress tests are useful when performed in the group with intermediate pretest probability of CAD. Thus the predictive value of exercise stress testing for diagnosing CAD depends quite heavily on pretest probability of CAD. In a large study of more than 5000 patients, the positive predictive values (PPVs) were reported to be $21 \%, 62 \%$ and $92 \%$ in low, intermediate and high pretest probability groups, respectively. Negative predictive values (NPVs) were $94 \%, 72 \%$ and $28 \%$ in the same low, intermediate and the high pretest probability groups [8]. Another study reported the exercise stress test to have a PPV of $44.4 \%$ and an NPV of $98.7 \%$ in the chest pain unit in an emergency department in more than 1000 patients [9].

\section{Sensitivity, Specificity and Referral Bias:}

Despite its low sensitivity and specificity $(67 \%$ and $72 \%$ respectively), exercise stress test remains the most widely used noninvasive test to determine the prognosis in patients with suspected or documented CAD. Of course the sensitivity and specificity will vary depending upon the population being selected for the testing. In addition, the exercise stress tests are very safe with risk of myocardial infarction and death is estimated to be 1 event per 2500 tests [10]. Coming from specialty practices, the exercise stress tests performed by the cardiologists would have what is called the Referral bias (Work up bias or Verification bias). This referral bias occurs when patients with an abnormal stress test results are referred to cardiac catheterization at a higher rate than those with a normal stress test result. In a meta-analysis of 21 studies involving more than 49000 patients, the catheterization referral rates were substantially higher for patients with abnormal exercise tests (42.5\%) compared with a normal test (4\%) [11]. The referral bias is almost universally unaccounted for in studies of exercise tests [12] and this phenomenon definitely brings the sensitivity of this test much lower than what we believe it to be true. 


\section{Prognostic Value of Exercise Testing:}

Of all the prognostic factors, exercise duration is most strongly associated with the risk of coronary events and cardiac death, independent of age and gender or known presence and severity of CAD [12].

A drop in systemic blood pressure with exercise can reflect severe $\mathrm{CAD}$ or left ventricular systolic dysfunction. In one study, exercise hypotension was associated with a 3 -fold higher risk of cardiac events over 2 years [13].

Exercise hypertension over $200-220 \mathrm{~mm} \mathrm{Hg}$ predicts future systemic hypertension in people with normal blood pressure [14].

Chronotropic incompetence (failure of the heart rate to increase with exercise) predicts all-cause and cardiovascular death [15]. Chronotropic incompetence is defined as less than $80 \%$ of the predicted value and less than $62 \%$ for patients taking a beta-blocker.

Heart rate recovery: The heart rate returns to normal pre-exercise level in several minutes once the exercise stops.

Impaired heart rate recovery (failure of the heart rate to decrease normally) predicts all-cause mortality and cardiovascular events, including sudden death, in healthy people and in patients in CAD [16].

Suggested thresholds for abnormal responses are [17]:

Upright: the heart rate should slow down by at least 12 beats/min at 1 minute.

Supine: at least 18 beats/min at 1 minute.

Sitting: at least 22 beats/min at 2 minutes.

The importance of frequent premature ventricular contractions (PVCs), couplets or short episodes of nonsustained ventricular tachycardia during exercise or recovery is unclear. Some studies show higher chances of cardiac event including death [18] while some other studies showed increased future cardiac death if those PVCs occurred during recovery but not during the exercise [19].

\section{Gender and Exercise Testing:}

The role of exercise stress test for CAD diagnosis in women is limited. Exercise-induced ST depression is less sensitive in women than in men, reflecting a lower prevalence of significant CAD and inability of many women to exercise maximum aerobic capacity. False positive stress tests are more common in women compared to men.

In addition, from prognosis point of view, exercise capacity is more important in men while chronotropic incompetence is more important in women [20].

\section{Incremental Value of other Stress tests:}

When the treadmill stress test findings establish that the possibility of CAD after the test is only in the range of intermediate range, the diagnosis and management remain somewhat uncertain. As physicians then, what we do do next? This uncertainty in the post-test likelihood may be reduced by using other tests.

If we decide to use an additional test, the post-test likelihood from the first test becomes the pre-test likelihood for the second test. For example, based on Bayes' theorem, an exercise-induced $1 \mathrm{~mm}$ depression in whom the pre-test likelihood was 15\%, the post-test likelihood would increase to only $27 \%$. However, if cardiac fluoroscopy was added to this test and that detects coronary calcium, the post-test likelihood would increase from $27 \%$ to $79 \%$. [21]. Likewise, if Echocardiography is added to the treadmill, the sensitivity goes up to $81 \%$ and specificity is up to $92 \%$. If nuclear imaging is added to the treadmill, it has the sensitivity of $88 \%$ and specificity of $90 \%$ [22].

\section{Pre-operative stress test:}

Preoperative evaluation' is a common task that most of the primary care physicians and many specialty docs have to perform. We need to assess them pre-operatively and try to predict the cardiac risk of events (infarction, death, stroke or $\mathrm{CHF}$ ). There are many studies showing low utility of noninvasive stress testing preoperatively. One study reported a sensitivity of $33 \%$, a specificity of $82 \%$ and positive predictive value of $27 \%$ in predicting death or myocardial infarction postoperatively [23]. That also means that by these criteria, $73 \%$ of the positive tests were falsely positive. In a similar study, patients were preoperatively evaluated with noninvasive stress tests. There was no significant association between the degree of ST depression and major cardiac complications.

Therefore the ACC/AHA 2007 (ACC: American College of Cardiology, AHA: American Heart Association) updates guide us to perform appropriate history and physical examination- without the need for additional testing. When further testing is indicated based on the algorithm, they should specify that such testing should only be pursued if the results will change management [24].

\section{Exercise stress testing in Asymptomatic people:}

The role of stress testing in asymptomatic people has always been controversial. Silent ischemia and silent CAD are known issues and can be unmasked by the stress tests. However one needs to be careful in selecting the population as to who can undergo the stress tests: it might lead to false positive results, further unnecessary testing and adverse outcome from the procedures and the tests.

On the other hand, $30-50 \%$ cases of first myocardial infarctions and sudden cardiac deaths in the US occur in people not known to have CAD from before. Therefore the early diagnosis and intervention will be of utmost importance. 
According to the ACC/AHA guidelines, there are no class I indications for performing a stress test in an asymptomatic person.

Class IIa include: asymptomatic person with Diabetes Mellitus especially planning for vigorous exercise. There is a higher risk of CAD in the presence of following factors: age more than 35, type II diabetes for more than 10 years, type I diabetes for more than 15 years; and Microvascular disease (eg. proliferative retinopathy, nephropathy or autonomic neuropathy).

Class IIb include: asymptomatic men older than 45 and women older than 55 with multiple cardiac risk factors, people involving public safety, and those with diseases with high risk for CAD (renal failure and peripheral vascular disease).

Because diabetics are at high risk for future CAD and cardiac events, another study, DIAD [25] was conducted to assess for risk of silent myocardial infarction in asymptomatic type II diabetics. Nuclear stress tests were performed on all these patients and they were followed up for 5 years. The number of cardiac events were the same in those studied and underwent the stress tests vs those who did not undergo the stress tests. This study simply proved that diabetics or otherwise, asymptomatic people need not have the stress tests. However this also goes to show that we need to be realistic about the stress tests as predicting for 5 years after a stress test is quite a long time and much can change over that period of time.

A positive stress test is a better predictor of angina than the occurrence of a major cardiac event. While the prediction of MI and death are considered the most important end points, the controversy surrounding the stress test, especially in asymptomatic people become much more intriguing when you bring in the sad demise in June 2008 of Tim Russert, "Meet the Press" host who died of sudden cardiac death. He had a stress test 6 weeks before his death. He presumably had some asymptomatic CAD and cardiac risk factors and was taking all his medications as recommended. His stress test was reported 'excellent'.

\section{Stress Testing after Myocardial Infarction:}

It is appropriate to consider the time frame of stress test after myocardial infarction with regard to the risks and the benefits of the test.

Based on the ACC/AHA guidelines, class I indications include: A. Before discharge for prognostic assessment, activity prescription or medical therapy evaluation (submaximal at about 4-7 days). B. Early after discharge for prognostic assessment, activity prescription or medical therapy evaluation (symptom limited at about 14-21 days). C. Later after discharge for prognostic assessment, activity prescription, medical therapy evaluation or cardiac rehabilitation evaluation (symptom limited at 3-6 weeks).
Duke Score and Stress Test:

Last but not the least, I would like to add the Duke Treadmill Score (DTS) while discussing the diagnostic and prognostic value of the stress test in relation to CAD. DTS includes the exercise capacity, ST changes and exercise-induced angina to predict the survival in patients suspected to have CAD [26]. Patients with low-risk score $(>4)$ reflecting longer exercise capacity and minimal or no ST changes will have an annual mortality rate of $0.25 \%$. As opposed to that, patients with high-risk scores $(<-10)$ will have the annual mortality rate of $5 \%$.

As per the ACC/AHA guidelines for the management of stable angina, medical therapy will be recommended for those with a risk of cardiac mortality $<1 \%$ per year and invasive angiography for those with a risk of cardiac mortality of $>3 \%$ [27]. For those with $1-3 \%$ risk of cardiac mortality, stress imaging will be recommended.

Table 2: Duke Treadmill Scoring System*

\begin{tabular}{|l|l|}
\hline Risk Group & Annual Mortality Rate \\
\hline Low $(>4)$ & $0.25 \%$ \\
\hline Intermediate $(-10-4)$ & $1.25 \%$ \\
\hline High $(>-10)$ & $5.0 \%$ \\
\hline
\end{tabular}

* The Duke treadmill score is calculated according to the following formula:

Exercise time ( $\mathrm{min})$

-5 (max ST-segment deviation [in mm, during or after exercise])

-angina score

where the score is 0 if there is no angina, 4 if angina occurs, and 8 if angina is the reason for stopping the test

Adapted from Mark DB, Shaw L, Harrell FE Jr, et al: Prognostic value of a treadmill exercise score in outpatients with suspected coronary artery disease. N Engl J Med1991;325:849-853.

\section{Future of cardiac Stress Tests:}

The future of stress tests might be in the imaging part of the study. This year at the ESC CONGRESS 2016, a study was presented and concurrently reported online [28] that the functional, noninvasive cardiac imaging using cardiovascular MR or myocardial perfusion scintigraphy was significantly better than was a current and well-regarded guideline-based approach to identifying patients with chest pains and suspected CAD who could safely avoid angiography thereby cutting the rate of unnecessary coronary angiography by $75 \%$.

Following the guideline formula adopted by the British National Institute for Health and Care Excellence (NICE) resulted in a $29 \%$ rate of unnecessary coronary angiography compared with rates of $7.5 \%$ using cardiovascular MR (CMR) and $7.1 \%$ using myocardial perfusion scintigraphy (MPS) in a multicenter randomized trial with 1,202 patients.

The rate of positive angiography was $12 \%$ in the NICE arm, $10 \%$ in the CMR arm and $9 \%$ in the MPS arm. The rate of major adverse cardiac event after 12 months follow up were $3 \%$ following the NICE protocol and $4 \%$ when screened by the CMR or with MPS. 
CMR having 5-10 fold greater spatial resolution than MPS will likely have higher diagnostic yield, will be better prognosticator, will have lower false-negative rate and thus more cost effective than MPS.

\section{Summary}

In my case report presented above, why did he not develop chest pressure/chest pains/palpitations while on the treadmill or soon thereafter? Why did he not develop ST/T changes diagnostic of ischemia? Why did he not develop any ischemia related arrhythmia? In all honesty, currently we do not have an answer to any of these questions; all we have are the possibilities, presumptions and predicaments!

Endothelial dysfunction, inflammation and plaque rupture are the most common presumed underlying mechanisms causing myocardial infarction. It is likely that is what happened in his case. By the time he came to our ER, his symptoms subsided, he was stabilized with medications. It is likely that a presumed plaque rupture must have 'stabilized' to some extent and the thrombotic clot must have been resolved by his body mechanisms, in addition by all the medical therapy given to him thus far. It is therefore likely that he 'passed' (did not fail) the test to everyone's surprise.

Again, to my knowledge, this is the first documented case where a patient did quite well on a treadmill test and pending Troponin value comes back abnormal thereafter proving that the patient had NSTEMI (non-ST elevation myocardial infarction).

How to manage a case like this in future? A patient should be managed optimally based on pre-test probability: symptoms, age, gender and cardiac risk factors. Pretest probability should dictate our course of action irrespective of the findings from a stress test.

We have come a long way from using treadmill 2000 years ago by the Chinese, Greeks and Romans for irrigation and construction to using it for diagnosing coronary artery disease (The Master's Steps) and then over time adding ECG, then echocardiography and nuclear imaging parts. Finally PET (positron emission tomography) and MR (magnetic resonance) are being added to help us diagnose the ischemic heart disease much more accurately improving its sensitivity, specificity and predictive value.

As the history tells us that the 25th US president, William McKinley was shot in Buffalo, NY in 1901 (only 35 miles away from my cardiology practice!) and eventually died because there was no X-ray machine then to locate the bullet in his body, we will not rest until we get to see the inside of the coronary arteries and make the diagnosis of CAD with $100 \%$ accuracy, non-invasively and without $\mathrm{X}$-rays!

\section{References}

1) Go AS, Mozaffarian D, Roger VL, Benjamin EJ, Berry JD, et al. (2014) American Heart Association Statistics Committee and Stroke Statistics Committee. Circulation. 129: e28-e292.

2) Heidenreich PA, Trogdon JG, Khavjou OA, Butler J, Dracup K, et al. (2011) Forecasting the future of cardiovascular disease in the United States: a policy statement from the American Heart Association.123: 933-944.

3) Kleindorfer D, Khoury J, Broderick JP, Rademacher E, Woo D, et al. (2009) Temporal trends in public awareness of stroke: warning signs, risk factors, and treatment. Stroke 40: 2502-2506.

4) Connolly HM, Oh JK. Echocardiography. In: Bonow RO, Mann DL, Zipes DP et al. ( 2011) Braunwalds's Heart Disease: A textbook of cardiovascular medicine (9th edn).

5) Rifkin RD, Hood WB Jr (1977) Bayesian analysis of electrocardiographic exercise stress testing. N Engl J Med 297:681-686.

6) Diamond GA, Forrester JS (1979) Analysis of probability as an aid in the clinical diagnosis of coronary artery disease. N Engl J Med 300:1350-1358

7) Grundy SM, Pasternak R, Greenland P, Smith S Jr, Fuster V, et al. (1999) Assessment of cardiovascular risk by use of multiple-riskfactor assessment equations: a statement for healthcare professionals from the American Heart Association and the American College of Cardiology. Circulation 100: 1481-192.

8) Morise AP (2000) Are the AA/AHA guidelines for exercise testing for suspected CAD correct? Chest.118:535-541.

9) Gibler BW, Ruyon JP, Levy RC, et al. (1995) A rapid diagnosis and treatment center for patients with chest pain in the emergency department. Ann Emerg Med 25:1-8.

10) Gibbons RJ, Balady GJ, Bricker JT, Chaitman BR, Fletcher GF, et al. (2002) ACC/AHA 2002 guideline update for exercise testing: summary article. A report of the American College of Cardiology/American Heart Association Task Force on Practice Guidelines (Committee to Update the 1997 Exercise Testing Guidelines). J Am Coll Cardiol 40:1531-1540.

11) Ladapo, JA, Blacker S, Elashoff, M, Federspiel JJ, Vieira DL, et al. (2013) Clinical Implications of Referral Bias in the Diagnostic Performance of Exercise Testing for Coronary Artery Disease. J Am Heart Assoc. 2: e000505.

12) Arena R, Myers J, Williams MA, Gulati M, Kligfield P, et al (2007) Assessment of functional capacity in clinical and research settings: a scientific statement from the American Heart Association Committee on Exercise, Rehabilitation, and Prevention of the Council on Clinical Cardiology and the Council on Cardiovascular Nursing. Circulation 116:329-343.

13) Dubach P, Froelicher VF, Klein J, Oakes D, Grover-McKay M, et al. (1988) Exercise-induced hypotension in a male population. Criteria, causes, and prognosis. Circulation 78:1380-1387.

14) Wilson NV, Meyer BM (1981) Early prediction of hypertension using exercise blood pressure. Prev Med 10:62-68.

15) Myers J, Tan SY, Abella J, Aleti V, Froelicher VF (2007) Comparison of the chronotropic response to exercise and heart rate recovery in predicting cardiovascular mortality. Eur J Cardiovasc Prev Rehab $14: 215-221$

16) Cole CR, Blackstone EH, Pashkow FJ, Snader CE, Lauer MS, et al. (1999) Heart-rate recovery immediately after exercise as a predictor of mortality. N Engl J Med 341:1351-1357.

17) Kligfield P, Lauer MS (2006) Exercise electrocardiogram testing: beyond the ST segment. Circulation 114: 2070-2082. 
18) Beckerman J, Wu T, Jones S, Froelicher VF (2005) Exercise testinduced arrhythmias. Prog Cardiovasc Dis 47:285-305.

19) Frolkis JP, Pothier CE, Blackstone EH, Lauer MS (2003) Frequent ventricular ectopy after exercise as a predictor of death. N Engl J Med 348:781-790.

20) Daugherty SL, Magid DJ, Kikla JR, Hokanson JE, Baxter J, et al. (2011) Gender differences in the prognostic value of exercise treadmill test characteristics. Am Heart J 161: 908-914.

21) Bartel AG, Chen JT, Peter RH, Behar VS, Kong Y, et al. (1974) The significance of coronary calcification detected by fluoroscopy: a report of 360 patients. Circulation 49:1247-1253.

22) Al-Shehri, Halia, Gary Small, and Benjamin JW Chow. (2011) "Cardiac CT, MR, SPECT, ECHO, and PET: What test, when ?" Applied Radiology 5: 13.

23) Carliner NH, Fisher ML, Plotnick GD, Garbart H, Rapoport A et al. (1985) Routine preoperative exercise testing in patients undergoing major noncardiac surgery. Am J Cardiol 56:51-58.

24) Fleisher LA, Beckman JA, Brown KA, Calkins H, Chaikof EL, et al. (2007) ACC/AHA 2007 guidelines on perioperative cardiovascular evaluation and care for noncardiac surgery: a report of the American College of Cardiology/American Heart Association Task Force on Practice Guidelines (Writing Committee to Revise the 2002 Guidelines on Perioperative Cardiovascular Evaluation for Noncardiac Surgery) developed in collaboration with the American Society of Echocardiography, American Society of Nuclear Cardiology, Heart Rhythm Society, Society of Cardiovascular Anesthesiologists, Society for Cardiovascular Angiography and Interventions, Society for Vascular Medicine and Biology, and Society for Vascular Surgery. J Am Coll Cardiol. 50:e159-e242.

25) Young LH, Wackers FJ, Chyun DA, Davey JA, Barrett EJ, et al. (2009) Cardiac outcomes after screening for asymptomatic coronary artery disease in patients with type II diabetes: The DIAD Study: A randomized controlled trial: JAMA 301: 1547-1555.

26) Mark DB, Shaw L, Harrell FE, Hlatky MA, Lee KL, et al. (1991) Prognostic value of a treadmill exercise score in outpatients with suspected coronary artery disease. N Engl J Med 325:849-853.

27) Gibbons RJ, Chatterjee K, Daley J, Douglas JS, Fihn SD, et al. (1999) ACC/AHA/ACP-ASIM guidelines for the management of patients with chronic stable angina: a report of the American College of Cardiology/American Heart Association Task Force on Practice Guidelines (Committee on Management of Patients With Chronic Stable Angina). J Am Coll Cardiol 33: 2092-2197.

28) Greenwood JP (2016) The Clinical Evaluation of Magnetic Resonance Imaging in Coronary heart Disease 2 (CE-MARC2): JAMA.

Submit your manuscript to JScholar journals and benefit from:

ब Convenient online submission

ฯ Rigorous peer review

ฯ Immediate publication on acceptance

q Open access: articles freely available online

ब High visibility within the field

- Better discount for your subsequent articles

Submit your manuscript at

http://www.jscholaronline.org/submit-manuscript. 